\title{
Impact of economic factors and knowledge translation on public procurement for dental adhesive systems
}

\author{
Gabriela de Souza BALBINOT(a) \\ Roger Keller CELESTE(b) \\ Vicente Castelo Branco LEITUNE(a) \\ Fabricio Mezzomo COLLARES(a) \\ (a) Universidade Federal do Rio Grande do \\ Sul - UFRGS, School of Dentistry, Dental \\ Materials Department, Porto Alegre, \\ RS, Brazil. \\ (b) Universidade Federal do Rio Grande do Sul \\ - UFRGS, School of Dentistry, Department \\ of Preventive and Social Dentistry, Porto \\ Alegre, RS, Brazil.
}

Declaration of Interests: The authors certify that they have no commercial or associative interest that represents a conflict of interest in connection with the manuscript.

Corresponding Author:

Fabricio Mezzomo Collares

E-mail: fabricio.collares@ufrgs.br

https://doi.org/10.1590/1807-3107bor-2022.vol36.0020

Submitted: February 15, 2021

Accepted for publication: August 31, 2021

Last revision: November 3, 2021
Abstract: This study aimed to screen the public procurement for dental adhesives in a public health system and evaluate the variables associated with the type and cost of purchased materials. A time series was conducted with secondary data collated from the Brazilian Databank of Healthcare Prices (BDHP). All public procurements for adhesive systems registered from 2010 to 2019 were collated. The frequency of purchase was described, and a multiple linear regression model was used to assess the influence of unit price on predictor variables. Multinomial logistic regression was conducted to describe the influence of selected variables on the probability of purchase for different classes of adhesive systems. A total of 2,752 purchases were analyzed, and the total cost of these materials reached US $\$ 7,022,659.00$ in the 10 analyzed years. The 3-step Etch \& Rinse adhesives corresponded to $45.63 \%$ of the processes, with increased probability of being purchased over time. The process conducted by public universities in recent years, using the auction modality, presented lower unit prices. The year of purchase, the type of institutions, the institution's location, and the procurement modality influenced the procurement process. The performed analyses contribute to the understanding of the variables associated with the procurements for adhesive systems, providing valuable information for rationalizing public expenditure and for implementing evidence-based practices to guarantee cost-effective and clinically effective procedures for users of the Brazilian public healthcare system.

Keywords: Dental Cements; Public Health Dentistry; Translational Medical Research; Costs and Cost Analysis; Implementation Science.

\section{Introduction}

The influence of adhesive systems on the longevity of dental restorations has been shown in different studies. ${ }^{1-4}$ In the most recent meta-analysis that evaluated the clinical effectiveness of different adhesive systems, the 3-step etch \& rinse ( $3 \mathrm{E} \& \mathrm{Ra}$ ) adhesive system is still the class of adhesives with consistently lower annual failure rates (AFR) when compared to the other adhesive classes. ${ }^{1}$ While the AFR for 3E\&Ra is 3.1, the 2-step etch \& rinse (2E\&Ra) shows an AFR of 5.8 with inappropriate effectiveness in bonding procedures. When self-etch (SEa) adhesives are considered, the most recent data show a decrease in the AFR for the 2-step self-etch 
(2SEa) adhesive over time, surpassing 3E\&Ra. Current evidence from clinical and laboratory data support the proposed mechanisms behind the longevity of $3 \mathrm{E} \& \mathrm{Ra}^{1,5}$ and $2 \mathrm{Sea}^{6,7}$ adhesive systems and explain the weakness of the adhesive layer in 2E\&Ra. ${ }^{8}$

While it is essential to consider these differences in the decision-making process for purchasing adhesive systems in private clinical practice, the impact of this decision on a public health system takes on added importance due to the number of public resources. Knowledge translation and the implementation of healthcare technology assessments are essential for knowledge synthesis and exchange and the application of ethically sound and cost-effective procedures in healthcare treatments. ${ }^{9}$ The evaluation of healthcare technologies and economic assessments are valuable for supporting the adequate allocation of resources and understanding the standard of care in a particular place. ${ }^{10}$ Translating knowledge into policies and practices is a challenge, and several efforts have been made to understand the application of financial resources for rationing and prioritizing resources in the public health system. ${ }^{11,12,13}$ While the market of medicines and other healthcare products ${ }^{14,15}$ has been investigated, little is known about the economic impact of dental materials on these procurement processes. The global direct cost for treating dental disease reached US\$ 356.80 billion in $2015^{16}$ and it is one of the most expensive conditions to be treated in a health system. ${ }^{17,18}$ The price of materials may play a significant role in the total amount spent on oral health in a country. The economic impact of choosing outdated or novel products on a public health system is likely to be large due to purchase volume.

The implementation of healthcare technologies and the introduction of innovative strategies may be observed by screening the procurement process in a health system. ${ }^{19}$ The information about purchased materials is used by government and public agencies to control product prices, increase transparency, avoid fraud and waste, and grant social control over public investments. ${ }^{19,20}$ The factors associated with the procurement for dental adhesive systems could contribute to the understanding of knowledge translation in this field and of the impact of purchases on public expenditure and on clinical practice. Thus, this study aimed to screen the public procurement for dental adhesives in a public health system and evaluate the variables associated with the type and cost of purchased materials.

\section{Methodology}

This is a time series study. Secondary data were collated by one researcher from the Brazilian Databank of Healthcare Prices (BDHP; https://bps.saude.gov. br) of the Brazilian Ministry of Health, which is a public database that contains procurement processes in healthcare institutions funded by the Brazilian federal government. The data on all purchases made by public services were collated from January 1, 2010 to December 31, 2019, according to the different classes of adhesive systems: 3-step etch-and-rinse (3E\&Ra), 2-step etch-and-rinse (2E\&Ra), and self-etch (SEa), as shown in Figure 1. All information provided by the $\mathrm{BDHP}$ was collated and the variables of interest were selected based on their impact on the purchase process. The description of the material, date of purchase, state, procurement modality, the institution where the purchase was made, manufacturer, number of purchased items, and unit price were selected. The collated data were recategorized when appropriate (Figure 1). Each state was categorized according to the Brazilian macro-regions for demographic analysis of purchases. The procurement modality was divided according to their frequency into three categories: the most frequent ones were kept while the least frequent ones were grouped as "Other." The institutions where the purchase was made were classified as universities, other federal institutions, and municipal health councils as these were the categories found in the databank. The information about manufacturers was corrected for typos, and unknown manufacturers were grouped as "Other." The unit price was collected in Brazilian Reais (BRL). These values were adjusted for inflation according to the broad consumer price index (free translation of Índice Nacional de Preços ao Consumidor Amplo or IPCA). IPCA in December 2019 served as the basis for calculation of the inflation rate. The percent monthly inflation rate was collected in other analyzed years and used to calculate inflation-adjusted unit prices. The values were matched to the data from 
the BDHP based on the date of purchase and the unit prices were then multiplied. These values were then converted to American dollars (US\$) according to the exchange rate on the day of the purchase registered by the Central Bank of Brazil.

All analyses were performed using Stata 14 (StataCorp LLC, College Station, USA). Descriptive analysis was conducted for screening the number of the procurement process. The data were analyzed with bivariate tables, and statistical significance was tested with one-way analysis of variance. The inflation-adjusted price was used as the outcome variable in a multiple linear regression model using ordinary least squares. Prices that were outliers due to possible errors were removed from the adjusted model if the studentized residual was larger than 7.32 standard deviations. The removed observations (29) represented $1.0 \%$ of the total number of cases in the databank and meant prices higher than BRL 500.00. An interclass correlation showed $30.9 \%$ of the variability in unit prices may be assigned to the institution that made the purchase and then a clustering analysis was conducted to adjust the standard error for the effect of clustered observations.

The different classes of adhesives were used as the outcome variable in a multinomial logistic regression model. A bivariate analysis was performed, and statistical significance was assessed with the chi-square test. Multinomial logistic regressions were adjusted with selected variables (region, price, year, procurement modality, and type of institution). In regression analyses, prices were divided by 10 to improve the interpretation of the coefficients. The logistic model was used to estimate the average response associated with different variables in the model by calculating the predictive margin values based on the category of reference (3E\&Ra). The clustering effect was considered for this analysis, as $40.9 \%$ of the variability may be assigned to the institution according to the interclass correlation analysis.

\section{Results}

Data collection resulted in 2,781 procurement processes and 299,173 units of adhesive systems (Figure 2A). After outlier removal, 2,752 purchases were analyzed. 3E\&Ra appeared most frequently in the dataset, with 136,524 adhesives, representing $45.6 \%$ of the purchased materials. The total cost of adhesive systems was US $\$ 7,022,659$, and $49.4 \%$ of this value was spent on 3E\&Ra adhesives (Figure 2B). 2E\&Ra represents $37.4 \%$ of the purchased units, while the least frequent adhesive systems wereSEa (16.9\%). SEa presented higher prices when compared to 2E\&Ra (Figure 2; $\mathrm{p}<0.05$ ). The univariate analysis for the price in the linear model is shown in Table 1 . The most frequent categories were used as reference in the regression model. All variables were used on the multiple models (Table 2).

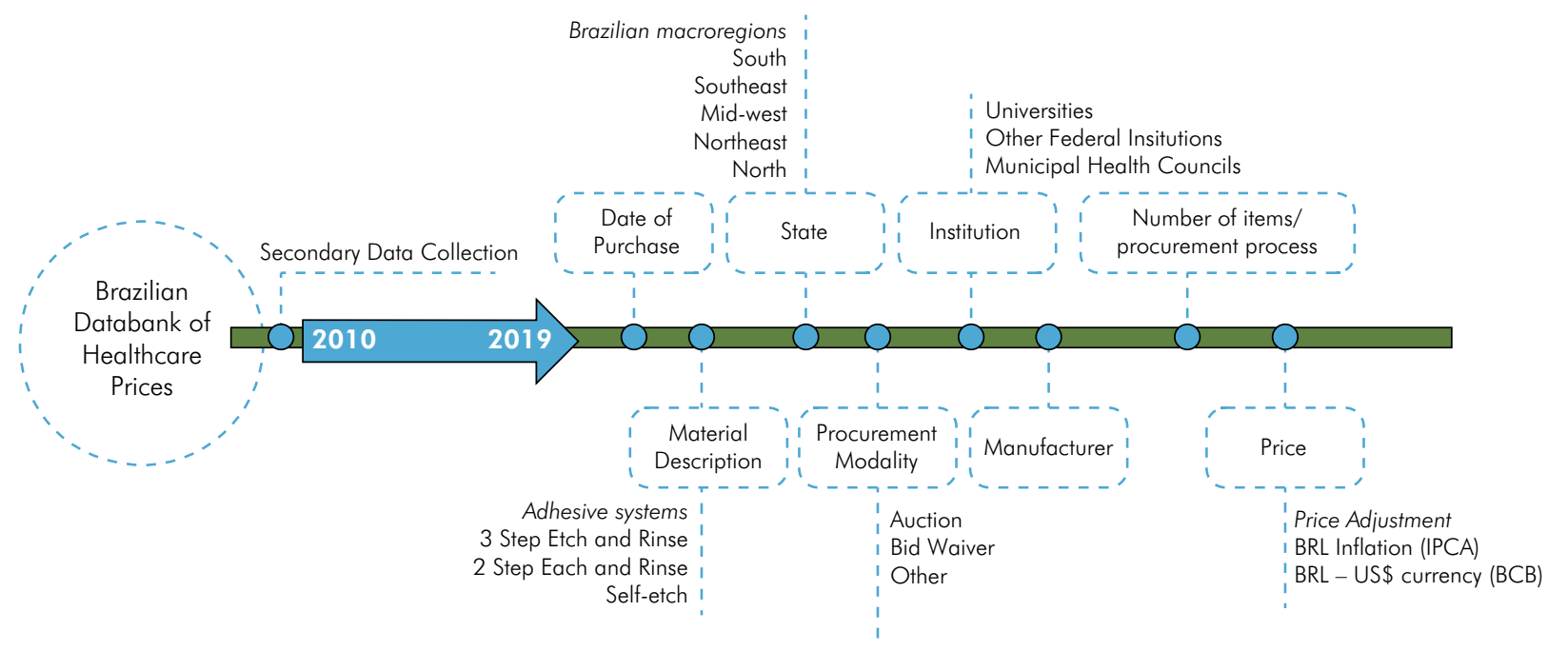

Figure 1. Flowchart showing data collection and categorization of variables for the analysis. 
A

Total number and \% of purchased adhesive systems. The total number of purchased adhesives was 299,173.

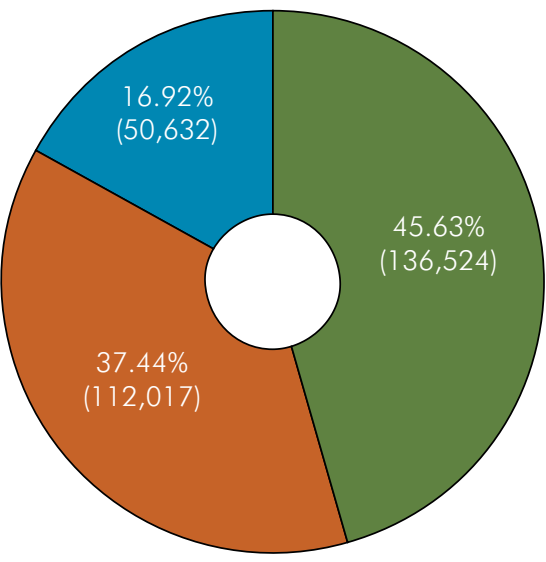

\section{B}

Overal cost (US\$) of adhesives and the \% cost for each adhesive system. The total cost of adhesive systems was US $\$ 7022659$

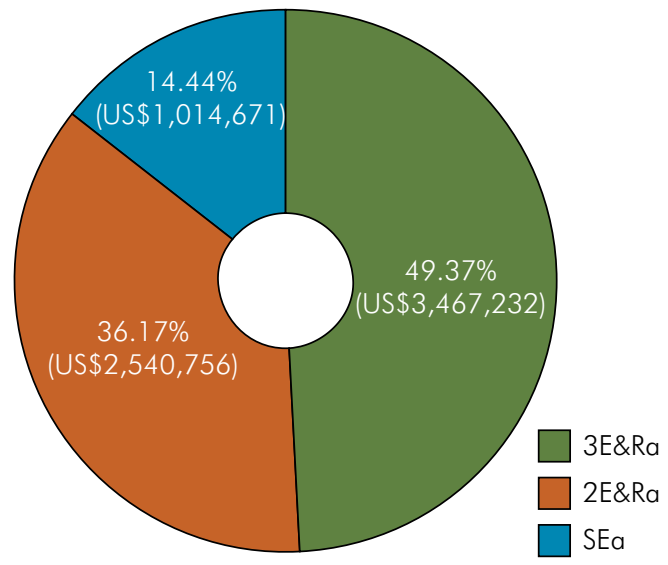

C

Mean and standard deviation of adhesive system prices (US\$)

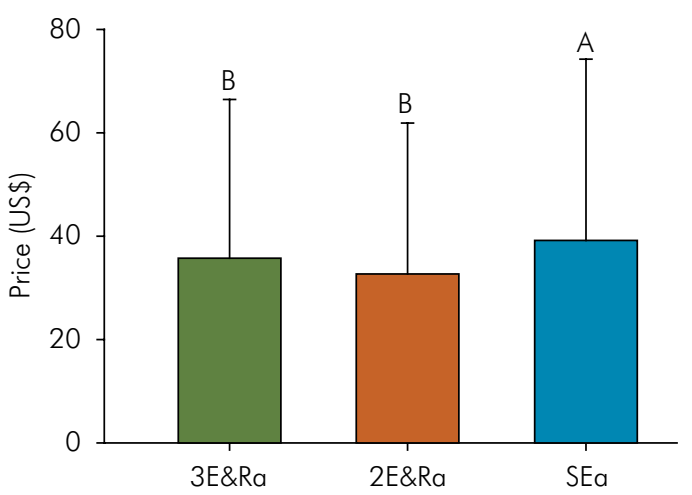

Different uppercase letters indicate statistically significant difference between different adhesive systems

Figure 2. Distribution of purchases among different adhesive systems.
Table 1. Average price and standard deviation calculated for each category.

\begin{tabular}{|c|c|c|c|c|}
\hline Variable & US\$ & SD & Frequency & $p$-value \\
\hline \multicolumn{5}{|l|}{ Adhesive system } \\
\hline $3 E \& R a$ & 35.69 & 30.81 & 1385 & \\
\hline $2 E \& R a$ & 32.74 & 29.27 & 975 & \\
\hline SEa & 39.19 & 35.19 & 392 & $<0.01$ \\
\hline \multicolumn{5}{|l|}{ Year } \\
\hline 2010 & 51.16 & 41.35 & 34 & \\
\hline 2011 & 57.20 & 46.58 & 130 & \\
\hline 2012 & 45.24 & 32.43 & 127 & \\
\hline 2013 & 37.13 & 2.59 & 259 & \\
\hline 2014 & 39.40 & 32.28 & 352 & \\
\hline 2015 & 38.55 & 29.94 & 294 & \\
\hline 2016 & 32.48 & 27.57 & 353 & \\
\hline 2017 & 32.48 & 34.22 & 415 & \\
\hline 2018 & 35.06 & 28.76 & 236 & \\
\hline 2019 & 21.28 & 16.82 & 481 & $<0.01$ \\
\hline \multicolumn{5}{|l|}{ Region } \\
\hline South & 42.64 & 32.91 & 609 & \\
\hline Southeast & 38.30 & 34.07 & 759 & \\
\hline Mid-west & 31.16 & 26.63 & 470 & \\
\hline Northeast & 29.58 & 26.03 & 641 & \\
\hline North & 30.52 & 31.27 & 302 & $<0.01$ \\
\hline \multicolumn{5}{|c|}{ Procurement modality } \\
\hline Auction & 32.98 & 30.29 & 2296 & \\
\hline Bid Waiver & 45.94 & 32.11 & 464 & \\
\hline Other & 31.76 & 34.25 & 21 & $<0.01$ \\
\hline \multicolumn{5}{|l|}{ Type of institution } \\
\hline Universities & 29.83 & 25.55 & 679 & \\
\hline $\begin{array}{l}\text { Other Federal } \\
\text { Institutions }\end{array}$ & 38.49 & 33.13 & 1879 & \\
\hline $\begin{array}{l}\text { Municipal } \\
\text { Health Councils }\end{array}$ & 23.32 & 21.10 & 223 & $<0.01$ \\
\hline \multicolumn{5}{|l|}{ Manufacturer } \\
\hline $3 \mathrm{M}$ & 44.15 & 32.48 & 1042 & \\
\hline Biodinâmica & 15.00 & 19.21 & 224 & \\
\hline Coltene & 17.84 & 11.86 & 7 & \\
\hline Densell & 36.16 & 22.94 & 23 & \\
\hline Dentisply & 34.17 & 34.15 & 287 & \\
\hline DFL & 16.58 & 10.87 & 34 & \\
\hline FGM & 25.62 & 18.96 & 400 & \\
\hline Kavokerr & 31.10 & 17.37 & 20 & \\
\hline Kulzer & 92.41 & 80.86 & 2 & \\
\hline Kuraray & 83.68 & 27.96 & 24 & \\
\hline Maquira & 10.22 & 8.68 & 166 & \\
\hline SDI & 21.77 & 10.05 & 4 & \\
\hline Technew & 14.00 & 3.73 & 12 & \\
\hline Vigodent & 21.99 & 22.60 & 113 & \\
\hline Other & 44.46 & 32.64 & 513 & $<0.01$ \\
\hline
\end{tabular}


The adjusted multiple linear regression model resulted in an $\mathrm{R}^{2}=25.4 \%$. The three different categories of adhesive systems were not associated with price $(p>0.05)$. The adhesives purchased through a bid waiver were US\$ 10.64 more expensive than those purchased by auction. Public universities and municipal health councils paid statistically lower values for adhesive units (Universities: US\$ -6.18 , $\mathrm{p}<0.01$; Municipal health councils: US $\$-7.34, \mathrm{p}<0.01$ ). Eight out of 14 manufacturers presented lower values for the unit price of adhesives when compared to the reference manufacturer $(3 \mathrm{M})$. The price was higher for one manufacturer than for the reference (Kuraray: 42.57; $\mathrm{p}<0.01$ ). The effect of time on the procurement for adhesives is detailed in Figure 3. The number of the procurement process was consistent with the number of purchased items over time. The increase in the number of purchased items was followed by the reduction of prices in all classes of adhesives, as confirmed by the linear model (Table 2).

Figures 4 and 5 show the predictive margins obtained from the adjusted multinomial logistic

Table 2. Adjusted price differences (Coeff) obtained from multiple linear regression on procurement processes $(\mathrm{n}=2,752)$ using unit price as response variable.

\begin{tabular}{|c|c|c|c|}
\hline Variable & Price & Coeff (US\$) & $95 \% \mathrm{Cl}$ \\
\hline \multicolumn{4}{|c|}{ Adhesive system (reference category: $3 \mathrm{E} \& \mathrm{Ra}$ ) } \\
\hline $2 \mathrm{E} \& \mathrm{Ra}$ & -1.35 & -5.24 & 2.51 \\
\hline SEa & 2.78 & -2.89 & 8.54 \\
\hline Year & -2.96 & -3.61 & -2.31 \\
\hline \multicolumn{4}{|c|}{ Region (reference category: Southeast) } \\
\hline South & 6.16 & 0.63 & 11.70 \\
\hline Mid-west & -3.62 & -9.91 & 2.67 \\
\hline Northeast & -1.57 & -6.57 & 3.43 \\
\hline North & -0.69 & -6.48 & 5.16 \\
\hline \multicolumn{4}{|c|}{ Procurement modality (reference category: Auction) } \\
\hline Bid waiver & 10.64 & 1.81 & 19.51 \\
\hline Other & 9.90 & -0.73 & 20.58 \\
\hline \multicolumn{4}{|c|}{ Type of institution (reference category: Other federal institutions) } \\
\hline Universities & -6.18 & -10.36 & -1.99 \\
\hline Municipal health councils & -7.34 & -11.94 & -2.77 \\
\hline \multicolumn{4}{|c|}{ Manufacturer (reference category: $3 \mathrm{M}$ ) } \\
\hline Biodinâmica & -27.68 & -32.86 & -22.49 \\
\hline Coltene & -21.19 & -26.95 & -13.57 \\
\hline Densell & -8.98 & -19.47 & 2.17 \\
\hline Dentisply & -9.03 & -20.79 & 2.71 \\
\hline DFL & -25.79 & -33.16 & -18.43 \\
\hline FGM & -18.27 & -22.87 & -13.63 \\
\hline Kavokerr & -6.69 & -17.20 & 3.82 \\
\hline Kulzer & 36.65 & -31.88 & 105.18 \\
\hline Kuraray & 42.57 & 32.97 & 52.18 \\
\hline Maquira & -27.76 & -32.65 & -22.87 \\
\hline SDI & -16.64 & -24.31 & -8.95 \\
\hline Technew & -29.11 & -38.31 & -19.91 \\
\hline Vigodent & -20.20 & -24.90 & -14.22 \\
\hline Outher & -7.36 & -16.57 & 1.85 \\
\hline Constant & 6026.0 & 4718.8 & 7335.9 \\
\hline
\end{tabular}

$R^{2}=25.4 \%$. Standard errors obtained with cluster adjustment based on the institution where the procurement was registered. 

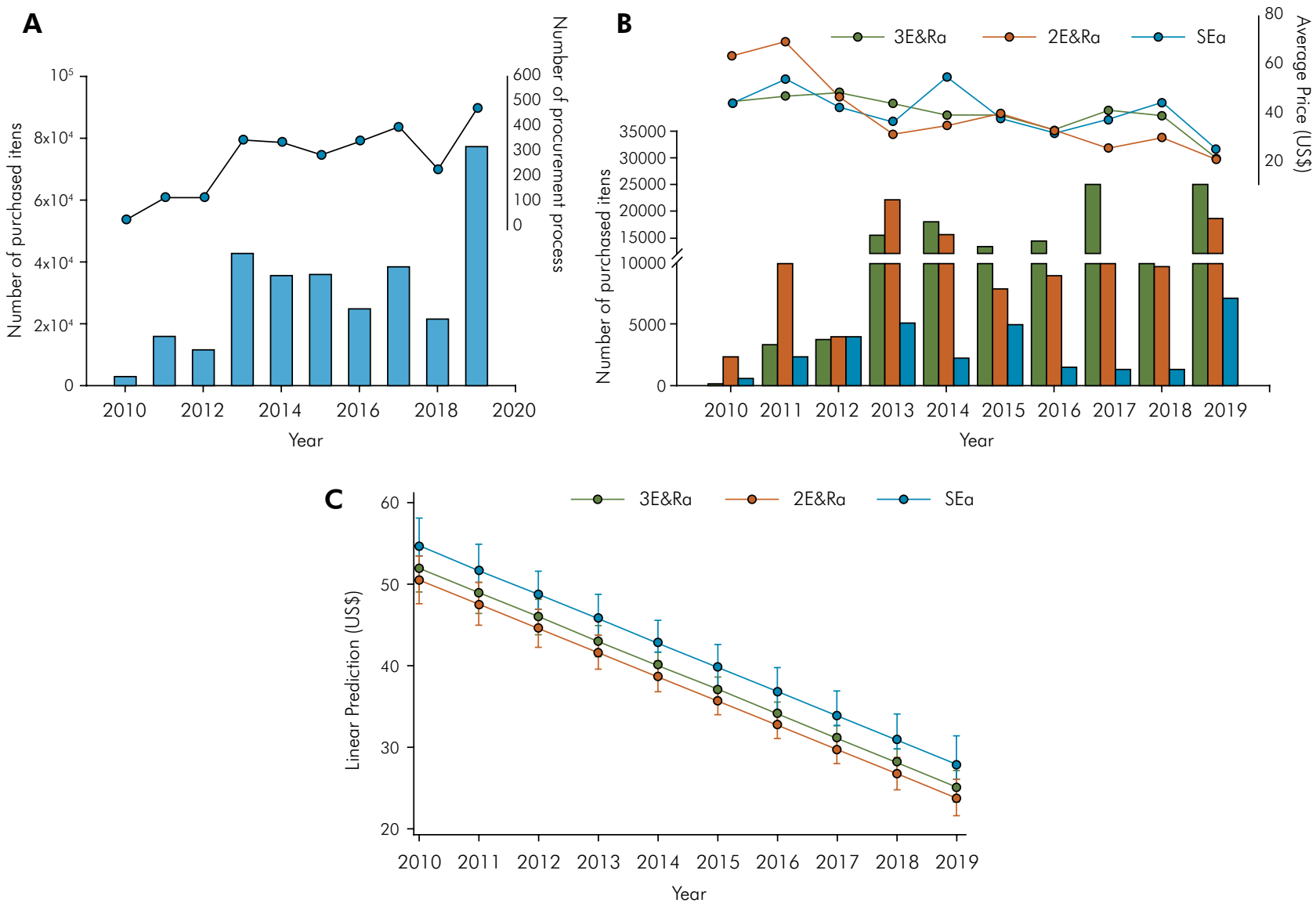

Figure 3. Time-related changes in procurements for adhesive systems.

A

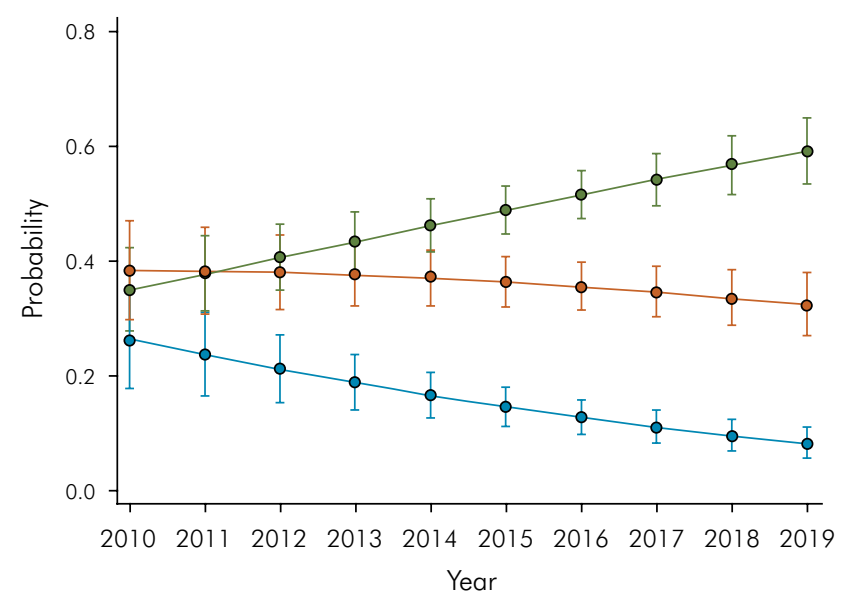

B

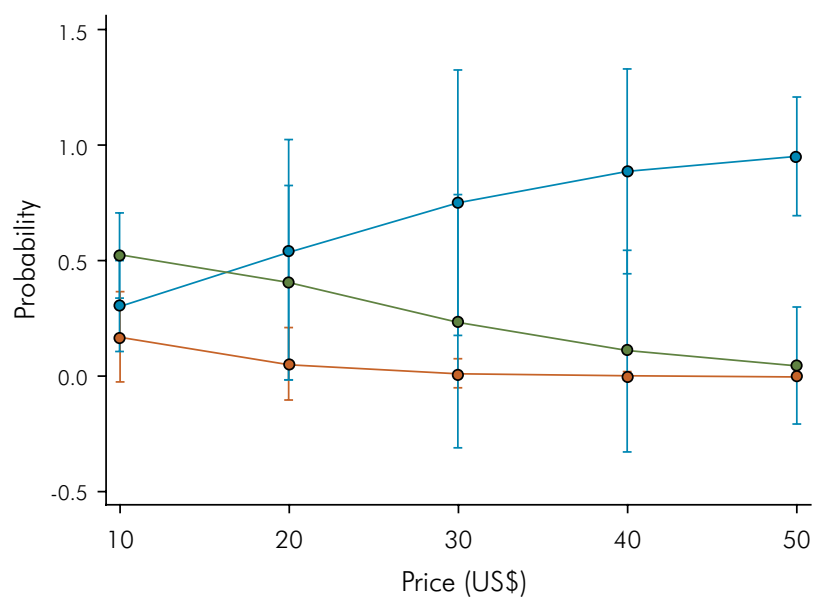

Predictive Margins with $95 \% \mathrm{Cls}$

- 3 E\&Ra $\quad$ - 2E\&Ra $\longrightarrow$ SEa

Figure 4. Predicted probabilities of purchase (margins) $[95 \% \mathrm{Cl}]$ in the adjusted logistic model showing the average response for the year and unit price. 
A

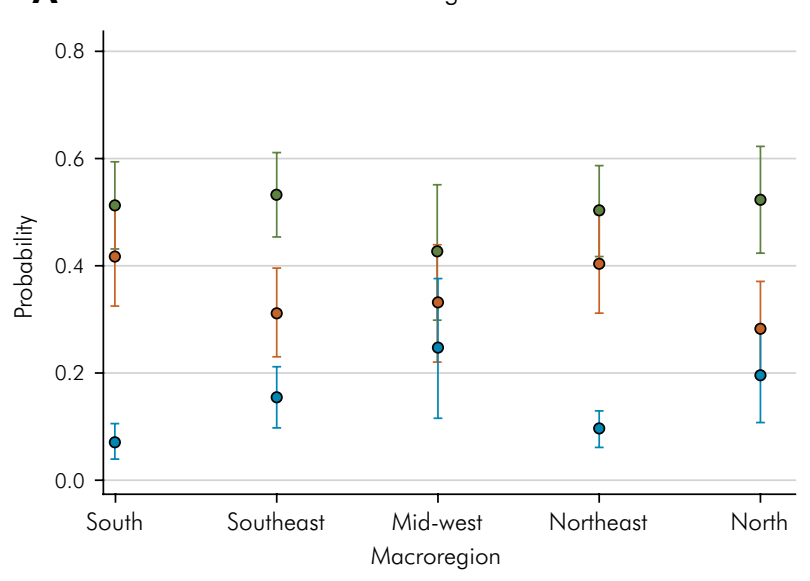

B

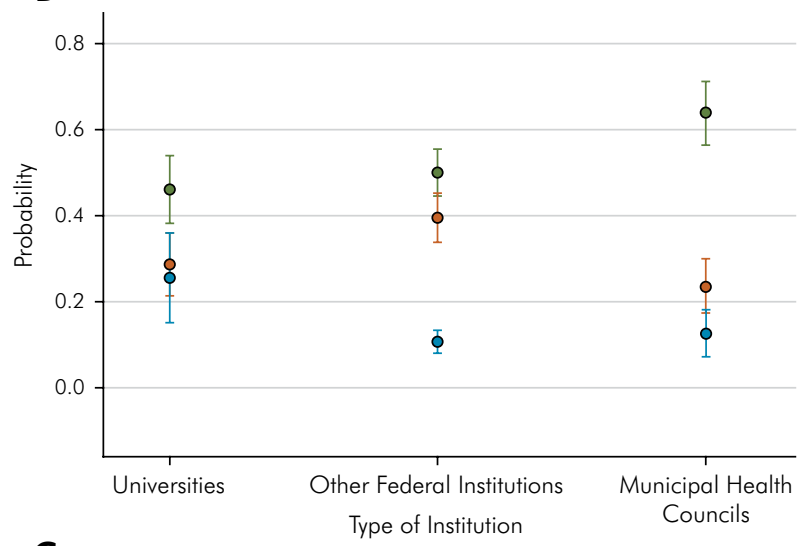

C

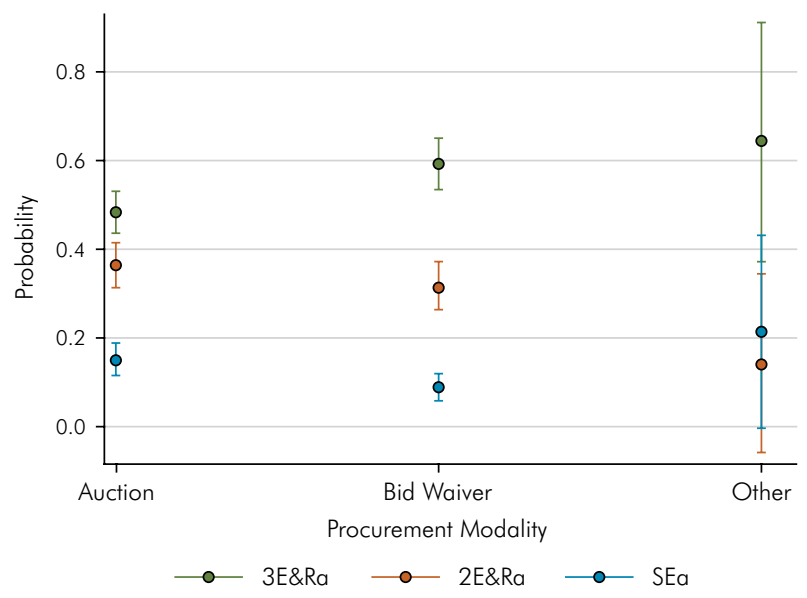

Figure 5. Predicted probabilities of purchase (margins) $[95 \% \mathrm{Cl}]$ in the adjusted logistic model with an average response for regions, institutions, and procurement modality.

regression model. The complete multinomial logistic regression analysis is shown in Tables 3 and 4 . The logistic model showed an increase in the probability of 3E\&Ra over the years (Figure 4A; Table 4) in comparison to the other adhesive systems (2E\&Ra; OR: 0.92; $\mathrm{p}<0.01$. SEa; OR: 0.82; $\mathrm{p}<0.01$ ). Price rises were shown to increase the odds to purchase SEa instead of 3E\&Ra (OR: 1.04; $\mathrm{p}<0.01)$. Public universities were more prone to purchase SEa adhesives when compared to 3E\&Ra than other federal institutions (OR: 2.86; $\mathrm{p}<0.01$ ).

\section{Discussion}

Understanding healthcare technologies and their cost in a public health system provides insights into the knowledge gap between materials and reallife practice development..$^{21}$ In the present study, a screening of the purchase of dental adhesive systems was conducted in the Brazilian public healthcare database. A 10-year analysis was performed, and the results were modeled to understand how the price and type of material influence the procurement for adhesives. The cost of adhesive systems reached US $\$ 7,022,659.00$ in the 10 analyzed years, and the unit price was reduced over time. 3E\&Ra was the most purchased adhesive system with an increasing probability of purchase in the final years of the period. The year of purchase, the type and location of institutions, and the procurement modality influenced the procurement process.

3E\&Ra adhesives represented $45.6 \%$ of the total number of purchases, going from $8.8 \%$ to $55.6 \%$ from 2010 to 2019 , accounting for $49.4 \%$ of the total cost of adhesive systems in the analyzed period (Figure 2). This was the first commercially available adhesive system, ${ }^{5}$ and it is known to result in lower annual failure rates until nowadays, ${ }^{1}$ which may explain the high percentage of these adhesives in the analyzed data (Figure 3). Although 2E\&Ra adhesives have been put on the market more recently, the reduction in bonding steps and the development of more user-friendly bonding strategies have made these materials highly attractive, even in the absence of reliable bonding ${ }^{1}$ Besides, the reduction in the number of clinical steps and the lower prices of these materials (Figure 2; $p<0.05$ ) may influence their purchase by public institutions. SE adhesives were the least purchased products $(16.9 \%)$, and, as the most expensive materials in this analysis, it is 
Impact of economic factors and knowledge translation on public procurement for dental adhesive systems

Table 3. Distribution in absolute numbers of purchases of different adhesive systems. Univariate analysis according to the type of adhesive system and chi-square univariate analysis for each variable.

\begin{tabular}{|c|c|c|c|c|c|}
\hline \multirow{2}{*}{ Adhesive system } & $3 E \& R a$ & $2 E \& R a$ & SEa & \multirow{2}{*}{ Total } & \multirow{2}{*}{$\mathrm{p}$-value } \\
\hline & $\%(N)$ & $\%(N)$ & $\%(N)$ & & \\
\hline \multicolumn{6}{|l|}{ Year } \\
\hline 2010 & $8.8(3)$ & 38.2 (13) & 52.9 (18) & $100(34)$ & \\
\hline 2011 & $32.2(40)$ & $38.7(48)$ & $29.0(36)$ & 100 (124) & \\
\hline 2012 & $29.3(37)$ & $38.8(49)$ & $31.7(40)$ & $100(126)$ & \\
\hline 2013 & 41.4 (147) & 37.7 (134) & $20.8(74)$ & 100 (355) & \\
\hline 2014 & 55.0 (190) & 31.5 (109) & $13.0(46)$ & 100 (345) & \\
\hline 2015 & $54.9(161)$ & $31.3(92)$ & $13.6(40)$ & 100 (293) & \\
\hline 2016 & $51.8(182)$ & $40.4(142)$ & $7.6(27)$ & 100 (351) & \\
\hline 2017 & $59.8(243)$ & $33.0(136)$ & 7.1 (29) & $100(406)$ & \\
\hline 2018 & 27.8 (1 13) & $44.2(104)$ & $7.6(18)$ & $100(235)$ & \\
\hline 2019 & 55.9 (269) & 30.7 (148) & $13.3(64)$ & 100 (481) & \\
\hline Total & $50.3(1385)$ & 35.4 (975) & 14.2 (392) & $100(2752)$ & 0.001 \\
\hline \multicolumn{6}{|l|}{ Region } \\
\hline South & $51.8(309)$ & $40.7(243)$ & $7.3(44)$ & 100 (596) & \\
\hline Southeast & $54.1(407)$ & 31.2 (235) & 14.5 (109) & 100 (751) & \\
\hline Mid-west & 39.7 (186) & 32.9 (154) & 27.3 (128) & $100(468)$ & \\
\hline Northeast & $50.9(324)$ & 39.1 (249) & $9.9(63)$ & $100(636)$ & \\
\hline North & 52.8 (159) & $31.2(94)$ & $15.9(48)$ & 100 (301) & \\
\hline Total & $50.3(1385)$ & 35.4 (975) & 14.2 (392) & $100(2752)$ & 0.001 \\
\hline \multicolumn{6}{|l|}{ Procurement modality } \\
\hline Auction & 47.9 (1089) & 36.5 (830) & $15.4(350)$ & $100(2269)$ & \\
\hline Bid waiver & 62.5 (289) & 30.9 (143) & 8.4 (39) & $100(462)$ & \\
\hline Other & $76.1(16)$ & $9.5(2)$ & $14.2(3)$ & $100(21)$ & \\
\hline Total & $50.3(1385)$ & 35.4 (975) & 14.2 (392) & $100(2752)$ & 0.001 \\
\hline \multicolumn{6}{|l|}{ Type of institution } \\
\hline Universities & $45.3(307)$ & 30.1 (204) & $24.5(166)$ & $100(677)$ & \\
\hline Other federal institutions & 50.4 (935) & $38.6(717)$ & 10.9 (203) & $100(1855)$ & \\
\hline Municipal health councils & $65.0(143)$ & $24.5(54)$ & $10.4(23)$ & $100(220)$ & \\
\hline Total & $50.3(1385)$ & $35.4(975)$ & $14.2(392)$ & $100(2752)$ & 0.001 \\
\hline
\end{tabular}

expected that their availability to public institutions would be reduced. Although SEa is presented as onestep and two-step systems, this differentiation was not present in the databank and, thus, all materials were grouped into a single category. Also, the heterogeneous chemical composition of SE adhesives over the years results in a different clinical behavior. ${ }^{7}$ Although some of these compositions combine good clinical performance with a simplified bonding procedure, ${ }^{2,22}$ it was not possible to observe a steady increase in the purchase of SE adhesive over the years (Figure 4 and Table 4).

The linear model regression indicated no impact of the classes of adhesive systems on unit price, while this variable was shown to modify the response in the multinomial logistic regression (Figures 4 and 5). The odds of buying 2E\&Ra were lower when compared to 3E\&Ra for every US\$ 10.00 increase 
Table 4. Multinomial logistic regression results using class of adhesives as response variable. Adjusted model to predict purchasing probability based on the different classes of adhesives.

\begin{tabular}{|c|c|c|c|c|}
\hline \multirow{3}{*}{ Variable } & \multicolumn{4}{|c|}{ Base outcome 3E\&Ra } \\
\hline & \multicolumn{2}{|c|}{$2 \mathrm{E} \& \mathrm{Ra}$} & \multicolumn{2}{|c|}{ SEa } \\
\hline & OR & $95 \% \mathrm{Cl}$ & OR & $95 \% \mathrm{Cl}$ \\
\hline Year & 0.925 & $0.875-0.978$ & 0.818 & $0.759-0.881$ \\
\hline Price* & 0.947 & $0.894-1.003$ & 1.043 & $0.988-1.100$ \\
\hline \multicolumn{5}{|c|}{ Region (Reference category: Southeast) } \\
\hline South & 1.383 & $0.795-2.406$ & 0.461 & $0.238-0.839$ \\
\hline Mid-West & 1.329 & $0.681-2.593$ & 2.097 & $0.815-5.398$ \\
\hline Northeast & 1.374 & $0.785-2.402$ & 0.629 & $0.332-1.190$ \\
\hline North & 0.906 & $0.489-1.681$ & 1.319 & $0.592-2.935$ \\
\hline \multicolumn{5}{|c|}{ Procurement modality (Reference category: Auction) } \\
\hline Bid waiver & 0.701 & $0.491-0.998$ & 0.445 & $0.273-0.726$ \\
\hline Other & 0.292 & $0.053-1.606$ & 1.109 & $0.254-4.835$ \\
\hline \multicolumn{5}{|c|}{ Type Of institution (Reference category: Other federal institutions) } \\
\hline Universities & 0.787 & $0.521-0.970$ & 2.859 & $1.401-5.832$ \\
\hline Municipal health councils & 0.461 & $0.289-0.736$ & 0.934 & $0.492-1.772$ \\
\hline Constant & 3.55 & $1.62-7.80$ & 3.90 & $2.00-7.70$ \\
\hline
\end{tabular}

*For every increase by US\$10.00; Standard errors obtained with cluster adjustment based on the institution where the procurement was registered.

in unit price $(\mathrm{OR}=0.95 ; \mathrm{p}<0.01)$. The opposite was found for SEa, which was more likely to be purchased than $3 E \& R a$ as the price increased (Table $4 ; \mathrm{OR}=1.04 ; \mathrm{p}<0.01)$. These differences may have an impact on the decision-making process in purchases by the public health system and affect the total value spent on adhesive systems as a direct cost of the public budget (Figure 2). Therefore, the findings of the present study should be considered in combination with the information about the effectiveness of adhesives in restorative treatments. By rationalizing the cost of dental treatments, the cost of a health intervention should be broadly recognized. The choice of the adhesive system may increase other direct and indirect costs, lead to the need for premature retreatment in case of failure, and cause a beyond price impact on the quality of life of the population. . $^{7,23,24}$

Changes in the type of adhesive system used may be related to the time between evidence generation and synthesis and knowledge translation into clinical practice. ${ }^{25}$ Unit prices were significantly influenced by the year of purchase, with a US\$
2.96 reduction for each year (Table $2 ; \mathrm{p}<0.01$ ). One could think that price decreases are due to an increment in purchased items (Figure 3). Increased market share leads to reduced production costs and enhanced industrial production, ${ }^{26,27}$ leading to lower prices. Furthermore, an increase in the number of manufacturers increases competition, controlling prices in the market and for the public health system. ${ }^{28,29}$ The marginal effect observed in the adjusted linear model confirms the prediction of price reduction over time (Figure 3C). Besides the effect on the price, the year of purchase predicted the type of purchased adhesive (Figure 4 and Table 4). 3E\&Ra is probably the most purchased adhesive over time when compared to 2E\&Ra (OR: 0.92; $p<0.01$ ) and SEa (OR: 0.81; $\mathrm{p}<0.01)$. These findings contribute to understanding the time-dependent knowledge translation observed in health treatments. ${ }^{25}$ While quick implementation of knowledge is desired, novel healthcare interventions are known to take decades to be implemented, ${ }^{30}$ and this may be the reason why the well-established $3 \mathrm{E} \& \mathrm{Ra}$ occupies a great market share in these procurements. 
Knowledge translation may be more easily observed at teaching institutions where researchers are responsible for choosing the materials that will be used in teaching activities. The influence of the type of institution was observed even after considering that the resources destined for each type are subjected to different degrees of spending cuts, ${ }^{31}$ and this may partially explain the lower cost of adhesives purchased by universities (-6.18; $\mathrm{p}<0.01)$. The translation of scientific knowledge in the university environment may be related to the adherence to evidence-based practice and, in combination with reduced prices, it may have contributed to the increased purchasing of SEa (OR: $2.86 ; \mathrm{p}<0.01$ ) when compared to other federal institutions. Knowledge dissemination from universities to other institutions is affected by socioeconomic and healthcare differences across Brazilian regions, ${ }^{32,33,34}$ explaining the variability in prices among them. In the cost analysis, the southern region paid higher values when compared to the southeastern region (US\$ 6.16; $p<0.01$ ), while the probability of purchasing the cheapest adhesive (2E\&Ra) was higher in the southern region (1.383; $\mathrm{p}<$ $0.01)$. This type of information could be used within region analysis to establish improved rationality in public purchases considering the peculiarities of each region and both state and municipal levels.

Differences in the procurement modalities were shown to influence both the price (Table 2) and the type (Figure 5C) of purchased materials. Auctioning is recommended by regulatory agencies as it guarantees equal conditions between bidders, allowing for better prices, higher transparency, and easy audit of the public system. ${ }^{35,36}$ As expected, when the institutions purchased adhesives through bid waivers, the prices were higher as no price limit or competition was observed. The impact of this amount of money in the long term and on the national scenario supports the government's recommendation and auctioning as the procurement modality of choice. ${ }^{37,38}$ The importance of the BDHP in the regulation of the Brazilian public healthcare system is also highlighted. This publicly available databank is an important tool for transparency in procurements and social control of healthcare prices, enabling planning of resource allocation in the healthcare system..$^{39}$ This study confirms that adherence to the recommendations of regulatory agencies is effective and allows combining the rational use of public expenditure with evidencebased practices, guaranteeing high quality of materials and treatments used in restorative dentistry in the public health system. ${ }^{40}$

The present study provides an overview of public procurements, improving the understanding of the impact of these procurements on the quality and cost of restorative treatments performed in a continental country, and it may also contribute to future analysis of the implementation of dental healthcare technologies in clinical practice. Understanding the variables related to these prices may provide the public health system with information that could help establish clinical and cost-effective procedures in restorative treatments. The impact of knowledge translation and how the implementation of evidencebased strategies may differ across a country are also noteworthy. This study supports the need for effective policies for evidence-based training to maintain and improve the quality of materials in the public health system. Continuous efforts to analyze the current standard of care may contribute to the improvement of strategies from bench top to chair side to increase the quality of treatments, focusing on better health outcomes and on their implementation in the population.

\section{Conclusion}

There was a preference for $3 E \& R$ adhesives in public purchases made by Brazil between 2010 and 2019. The price of adhesives was reduced in purchases made by public universities in recent years using procurement auction. The year of purchase positively predicted the purchase of $3 \mathrm{E} \& \mathrm{Ra}$, while price reduction increased the probability of 2E\&Ra purchase.

\section{Acknowledgments}

G.S.B would like to thank "Coordenação de Aperfeiçoamento de Pessoal de Nível Superior" (CAPES) - Brazil - Finance Code 001 - Fellowship. 


\section{References}

1. Peumans M, De Munck J, Mine A, Van Meerbeek B. Clinical effectiveness of contemporary adhesives for the restoration of non-carious cervical lesions: a systematic review. Dent Mater. 2014 Oct;30(10):1089-103. https://doi.org/10.1016/i.dental.2014.07.007

2. Peumans M, De Munck J, Van Landuyt K, Van Meerbeek B. Thirteen-year randomized controlled clinical trial of a two-step self-etch adhesive in non-carious cervical lesions. Dent Mater. 2015 Mar;31(3):308-14. https://doi.org/10.1016/i.dental.2015.01.005

3. Peumans M, Wouters L, De Munck J, Van Meerbeek B, Van Landuyt K. Nine-year clinical performance of a HEMA-free one-step self-etch adhesive in noncarious cervical lesions. J Adhes Dent. 2018;20(3):195-203. https://doi.org/10.3290/i.jad.a40630

4. Dijken JW. A prospective 8-year evaluation of a mild two-step self-etching adhesive and a heavily filled two-step etch-and-rinse system in non-carious cervical lesions. Dent Mater. 2010 Sep;26(9):940-6. https://doi.org/10.1016/i.dental.2010.05.009

5. Pashley DH, Tay FR, Breschi L, Tiäderhane L, Carvalho RM, Carrilho M, et al. State of the art etch-and-rinse adhesives. Dent Mater. 2011 Jan;27(1):1-16. https://doi.org/10.1016/i.dental.2010.10.016

6. Tian F, Zhou L, Zhang Z, Niu L, Zhang L, Chen C, et al. Paucity of nanolayering in resin-dentin interfaces of MDP-based adhesives. J Dent Res. 2016 Apr;95(4):380-7. https://doi.org/10.1177/0022034515623741

7. Van Meerbeek B, Yoshihara K, Yoshida Y, Mine A, De Munck J, Van Landuyt KL. State of the art of self-etch adhesives. Dent Mater. 2011 Jan;27(1):17-28. https://doi.org/10.1016/i.dental.2010.10.023

8. Tay FR, Pashley DH, Suh BI, Carvalho RM, Itthagarun A. Single-step adhesives are permeable membranes. J Dent. 2002 Sep-Nov;30(7-8):371-82. https://doi.org/10.1016/S0300-5712(02)00064-7

9. Liu W, Shi L, Pong RW, Dong H, Mao Y, Tang M, et al. Determinants of knowledge translation from health technology assessment to policy-making in China: from the perspective of researchers. PLoS One. 2018 Jan;13(1):e0190732. https://doi.org/10.1371/journal.pone.0190732

10. Langer A. A framework for assessing Health Economic Evaluation (HEE) quality appraisal instruments. BMC Health Serv Res. 2012 Aug; 12(1):253. https://doi.org/10.1186/1472-6963-12-253

11. Brazier J, Ara R, Azzabi I, Busschbach J, Chevrou-Séverac H, Crawford B, et al. Identification, review, and use of health state utilities in cost-effectiveness models: an ISPOR good practices for outcomes research task force report. Value Health. 2019 Mar;22(3):267-75. https://doi.org/10.1016/i.jval.2019.01.004

12. Brouwers MC, Kho ME, Browman GP, Burgers JS, Cluzeau F, Feder G, et al. AGREE II: advancing guideline development, reporting and evaluation in health care. J Clin Epidemiol. 2010 Dec;63(12):1308-11. https://doi.org/10.1016/i.jclinepi.2010.07.001

13. Decimoni TC, Leandro R, Rozman LM, Craig D, Iglesias CP, Novaes HM, et al. Systematic review of health economic evaluation studies developed in Brazil from 1980 to 2013. Front Public Health. 2018 Feb;6:52. https://doi.org/10.3389/fpubh.2018.00052

14. Brown GC, Brown MM. Value-based medicine and pharmacoeconomics. Dev Ophthalmol. 2016;55:381-90. https://doi.org/10.1159/000431205

15. Forné C, Subirana I, Blanch J, Ferrieres J, Azevedo A, Meisinger C, et al. A cost-utility analysis of increasing percutaneous coronary intervention use in elderly patients with acute coronary syndromes in six European countries. Eur J Prev Cardiol. 2021 May;28(4):408-17. https://doi.org/10.1177/2047487320942644

16. Righolt AJ, Jevdjevic M, Marcenes W, Listl S. Global-, regional-, and country-level economic impacts of dental diseases in 2015. J Dent Res. 2018 May;97(5):501-7. https://doi.org/10.1177/0022034517750572

17. Listl S, Grytten JI, Birch S. What is health economics? Community Dent Health. 2019 Nov;36(4):262-74. https://doi.org/10.1922/CDH_4581Listl13

18. Peres MA, Macpherson LM, Weyant RJ, Daly B, Venturelli R, Mathur MR, et al. Oral diseases: a global public health challenge. Lancet. 2019 Jul;394(10194):249-60. https://doi.org/10.1016/S0140-6736(19)31146-8

19. Torbica A, Cappellaro G. Uptake and diffusion of medical technology innovation in Europe: what role for funding and procurement policies? J Med Mark. 2010 Jan;10(1):61-9. https://doi.org/10.1057/jmm.2009.48

20. Kastanioti C, Kontodimopoulos N, Stasinopoulos D, Kapetaneas N, Polyzos N. Public procurement of health technologies in Greece in an era of economic crisis. Health Policy. 2013 Jan;109(1):7-13. https://doi.org/10.1016/i.healthpol.2012.03.015

21. Udeh BL. Economic evaluation studies. Chest. 2020 Jul;158(1 1S):S88-96. https://doi.org/10.1016/i.chest.2020.03.008

22. Van Meerbeek B, Yoshihara K, Van Landuyt K, Yoshida Y, Peumans M. From Buonocore's pioneering acid-etch technique to self-adhering restoratives: a status perspective of rapidly advancing dental adhesive technology. J Adhes Dent. 2020;22(1):7-34. https://doi.org/10.3290/i.jad.a43994

23. Schwendicke F, Meyer-Lueckel H, Stolpe M, Dörfer CE, Paris S. Costs and effectiveness of treatment alternatives for proximal caries lesions. PLoS One. 2014 Jan;9(1):e86992. https://doi.org/10.1371/journal.pone.0086992

24. Listl S, Galloway J, Mossey PA, Marcenes W. Global Economic Impact of Dental Diseases. J Dent Res. 2015 Oct;94(10):1355-61. https://doi.org/10.1177/0022034515602879 
- Impact of economic factors and knowledge translation on public procurement for dental adhesive systems

25. Morris ZS, Wooding S, Grant J. The answer is 17 years, what is the question: understanding time lags in translational research. J R Soc Med. 2011 Dec;104(12):510-20. https://doi.org/10.1258/irsm.2011.110180

26. Wright TP. Factors Affecting the Cost of Airplanes. J Aeronaut Sci. 1936 Feb;3(4):122-8. https://doi.org/10.2514/8.155

27. Schmidt O, Hawkes A, Gambhir A, Staffell I. The future cost of electrical energy storage based on experience rates. Nat Energy. 2017 Aug;2(8):17110. https://doi.org/10.1038/nenergy.2017.110

28. Farm A. Pricing in practice in consumer markets. J Post Keynes Econ. 2020 Jan;43(1):61-75. https://doi.org/10.1080/01603477.2019.1616562

29. Farm A. Pricing and price competition in consumer markets. J Econ. 2017 Mar;120(2):119-33. https://doi.org/10.1007/s00712-016-0503-7

30. Dobrow MJ, Goel V, Upshur RE. Evidence-based health policy: context and utilisation. Soc Sci Med. 2004 Jan;58(1):207-17. https://doi.org/10.1016/S0277-9536(03)00166-7

31. Doniec K, Dall'Alba R, King L. Brazil's health catastrophe in the making. Lancet. 2018 Sep;392(10149):731-2. https://doi.org/10.1016/S0140-6736(18)30853-5

32. Albuquerque MV, Viana AL d'Ávila, Lima LD, Ferreira MP, Fusaro ER, lozzi FL. Regional health inequalities: changes observed in Brazil from 2000-2016. Cienc Saúde Coletiva. 2017 Apr;22:1055-64. https://doi.org/10.1590/1413-81232017224.26862016

33. Peres MA, Barbato PR, Reis SC, Freitas CH, Antunes JL. [Tooth loss in Brazil: analysis of the 2010 Brazilian Oral Health Survey]. Rev Saúde Pública. 2013 Dec;47 Suppl 3:78-89. Portuguese. https://doi.org/10.1590/S0034-8910.2013047004226

34. Giordani JMA, Amaral Júnior OL, Hugo FN, Hilgert JB, Giordani JMA, Amaral Júnior OL, et al. Factors associated with service user embracement by Primary Health Care teams in Brazil, 2012: a cross-sectional study. Epidemiol Serv Saúde. 2020;29(5). https://doi.org/10.1590/s1679-49742020000500017

35. Brasil. Lei no 8.666, de 21 de junho de 1993. Regulamenta o art. 37, inciso XXI, da Constituição Federal, institui normas para licitações e contratos da Administração Pública e dá outras providências. Diário Oficial União. 1993 Jun 22.

36. Pereira CA. Public procurement in Brazil: general rules. Rochester: Social Science Research Network; 2012.

37. Kohler JC, Mitsakakis N, Saadat F, Byng D, Martinez MG. Does pharmaceutical pricing transparency matter? Examining Brazil's public procurement system. Global Health. 2015 Aug;11(1):34. https://doi.org/10.1186/s12992-015-0118-8

38. Pontes MA, Tavares NU, Francisco PM, Naves J OS. Investment of financial resources for the procurement of medicines for primary care in Brazilian municipalities. Cienc Saúde Coletiva. 2017 Aug;22:2453-62. https://doi.org/10.1590/1413-81232017228.18282016

39. Ministério da Saúde (BR). Banco de preços em Saúde. Brasília, DF: Ministério da Saúde; 2020[cited 2020 Apr 29]. Available from: https://www.saude.gov.br/gestao-do-sus/economia-da-saude/banco-de-precos-em-saude

40. Gombos K, Herczeg R, Erőss B, Kovács SZ, Uzzoli A, Nagy T, et al. Translating scientific knowledge to government decision makers has crucial importance in the management of the COVID-19 pandemic. Popul Health Manag. 2021 Feb;24(1):35-45. https://doi.org/10.1089/pop.2020.0159 